\title{
PERSPECTIVE
}

\section{The way COVID-19 transforms our sexual lives}

\author{
Issam Nessaibia $\mathbb{I D}^{1,2 \bowtie}$, Raffaello Sagese ${ }^{2}$, Leo Atwood $\mathbb{D}^{3}{ }^{3}$, Zihad Bouslama ${ }^{1}$, Luigi Cocci ${ }^{2}$, Tarek Merad ${ }^{1}$ and Abdelkrim Tahraoui ${ }^{4}$
}

(c) The Author(s), under exclusive licence to Springer Nature Limited 2021

During the early stages of the outbreak, insufficient attention was paid to the impact on sexual function, which is logical in the face of potentially harmful and fatal infections. It is well documented that any close contact ( 6 feet or $2 \mathrm{~m}$ ) with an infected person can result in exposure to SARS-CoV-2 so while coronavirus disease: (COVID-19) may not be "sexually transmitted" (through semen or vaginal fluids) the risks of proximal exposure are great-whether the activity is engaged in is sexual or not. For the last 3-4 months, scientific studies have shown that a mild or severe coronavirus infection can lead to sexual complications and prolonged libido problems as well as erectile dysfunction. Besides, following some barrier gestures during "face-to-face" sexual intercourse can be challenging. This paper focuses on the construction and prefiguration of a new paradigm of sexuality that distinguishes and associates sexual relations that take place in the presence of a real partner and those that take place within the context of a range of digital environments qualified as "virtual" that can provide safe contexts for erotic imagination and intimacy while both communicating and maintaining arousal. Together, they offer a vehicle for fantasy and entertainment of sexual arousal towards private pleasure.

IJIR: Your Sexual Medicine Journal (2022) 34:117-119; https://doi.org/10.1038/s41443-021-00494-9

"Not recommended"; "to be adapted" or "safe"; sexual intercourse is subject to vague recommendations that differ from country to country. We do know that Covid-19 is transmitted mainly by human-to-human contact via respiratory droplets. Touching, kissing, or even closely talking are behaviors we have had to break over the past year. A few countries, such as Italy, explicitly invite partners who are not cohabiting to limit physical interaction, even sexual intimacy, and, if appropriate, to consider "wearing a mask that covers the nose and mouth". Other researchers recommend choosing certain less risky positions or having "indirect" sex (simultaneous masturbation, remote-controlled sex toys...), which does not involve touching [1]. Whether the virus can pass through semen as well as vaginal secretions is not yet known. No scientifically validated study shows sexual transmission, unlike the human immunodeficiency viruses (HIV) and the Zika virus (ZIKV). If so, why do we need all these guidelines in our intimacy?

Although the virus-in its specific ontology-reaches some of us, it is above all the sanitary and political measures implemented that affect all populations. Together, these measures lead to both individual and collective reactions, psychosocial effects, in several cases psychopathological outcomes. Furthermore, these measures influence private relational sex life, sexual function (desire, arousal, erection, lubrication, orgasm, and sexual satisfaction) [2].

Apart from the fact that we could spread this virus, do we still want to be allosexual? According to the French Institute of Public Opinion (IFOP), it would seem not. During the first lockdown, more than $25 \%$ of couples reported having no or less sexual activity than usual. The libido, along with our social, cultural, and professional life, has diminished. At least for some, there is no consensus either on the frequency or on the satisfaction of intercourse. The fact is that, as Alain Giami explains, for many couples, confinement increases eroticization; for others, it decreases it [1]. From a purely "physical" point of view, the virus has also disrupted our sexuality. A study conducted on subjects in Rome observed the persistence of symptoms 60 days following the outbreak of this pandemic. One in two respondents described three if not more symptoms after that interval. The most frequently experienced complications: significant fatigue (in 53\% of cases), dyspnea (difficulty in breathing), and joint pain. Such context is likely to impact the quality, frequency of sexual relationships and may even generate a certain apprehension [3].

Meeting a sexual partner has never been more complicated than in 2020. Due to the closure of public places (bars, restaurants, discotheques) and the restriction of close-proximity discourse in addition to professional meetings, the fear of contamination has resulted. Based on a cross-sectional study among couples in Turkey, $35 \%$ of singles say that fear of the virus has forced them to not have sex with someone they like. This situation has particularly impacted the younger generation in an age where sexuality and body connections remain central [4]. Among the people that this situation has impacted are those with a non-majority sexual orientation. Often, they have found themselves locked in a family and friend circle that is not very appreciative or supportive. For example, individuals in both the Asian and the LBGT communities experienced an increased wave of discrimination due to xenophobia and racism around the pandemic. Older LBGT adults are at more risk of isolation than younger and this isolation can exacerbate thus other sexual health issues [5].

Turban et al. gave a useful guide for health care professionals (HCPs) to be aware of when dealing with sexual and gender minorities (SGM) to support their sexual health. The authors' point

\footnotetext{
${ }^{1}$ Environmental Research Center (CRE), Badji-Mokhtar Annaba University, Annaba 23000, Algeria. ${ }^{2}$ Gabinetto di Psicologia (REFLETO), Via Francesco Saverio Nitti 28, Rome, Italy. ${ }^{3}$ University of Alberta, Edmonton, Alberta, Canada. ${ }^{4}$ Laboratory of Applied Neuro-Endocrinology, Badji-Mokhtar University, Annaba, Algeria. ${ }^{\infty}$ email: issamland@yahoo.fr
} 
out the "particular vulnerability" of SGMs to sexual stigma (stemming from the "historical trauma of other pandemics, such as AIDS"), and the impact of such stigma and shame cannot be overstated when addressing sexual health of LGBTQ individuals [6]. In addition, to recognizing the influence of shame and stigma on individuals' sexual health behaviors, acknowledging the diversity of LGBTQ persons' sexual health expressions and tools is essential for health professionals in addressing the sexual health needs of their patients. Additionally, while recent studies on users of online geospatial networking applications have included specific populations such as gay men, younger app users, and transgender women; many other identities reside under the LGBTQ banner and employ multiple alternative networking approaches [7].

About $87 \%$ of singles abstained from sex during the initial confinement, although dating continued even across the pandemic. Numerous surveys indicate the creativity that takes place in long-distance relationships. Perhaps this is the bright side of the whole situation: we can benefit, in our era, from a myriad of social networks, dating sites, and other forums [1].

Human beings have reinvented themselves just as they have during any other crisis that disrupts the way we function. The concept of virtual sexuality, emerging in much greater detail than previously, is being explored and measured very carefully by scientific, distinguishing between the different technologies used (texting, messaging, and photo and video exchanges), the practices and content consumed, and the known or unknown and established or unestablished partners with whom it takes place. Above and beyond the simple receptive consumption of explicit content facilitating individual masturbation, we observe the use of interactive technologies allowing contact between people either with face-to-face meetings or to the realization of virtual erotic scenarios based on the interactive participation (whether charged for or not) of each individual [8]. Everyone can create their pornography as advocated in an online advertisement the new Pornhub branch. What is the cause? Experts believe it is a combination of factors: anxiety combined with the health situation, financial difficulties caused by the crisis, increasing depression, withdrawal... $40 \%$ of Swiss people say they feel more stressed than before the beginning of the pandemic. Sexuality should provide such a space for personal growth and development but no longer can do so. The current difficulties (lack of outings, restricted living spaces, limited access to contraception, reduced purchasing power) have made the territories of intimacy shrink. The last remaining place where we have any autonomy is still through virtual sex [8].

Utilization of the web to sustain active sexual engagement came up as an effective substitute for reducing the gap between partners or expanding online dating relationships. The predominant guidance for estranged couples was to keep in regular digital contact to alleviate longing and lack. This was the impetus behind sexting, webcam dating, or hot calling that left the couple more disinhibited [9]. Webcam activity, sometimes also with the possibility of having sex toys, could generate the ability to enlarge the future sexual catalog. Practicing online sex with the regular partner at a distance from home has helped some to maintain their lust alive and to satisfy it so that it can be fulfilled once the pandemic is over [10].

Independently, based on a recent survey, $36 \%$ of the unfaithful would have defied the restrictions by visiting their illegitimate partner. Could the promiscuity link to confinement have, in turn, brought infidelity among those not previously involved, revealing marital dysfunctions? Being in the same place has sometimes allowed us to notice what we no longer know about each other while a certain intimacy lost amid the frenzy of societal hyperactivity, says author Kristina Coop Gordon: the result might have been putting many couples in front of their gaps to fill [11]. However, at a time of uncertainty, in which social contacts are reduced to a minimum, the need for both physical and intellectual encounters blurs the commonly accepted definition of fidelity. Should the fact of having virtual sex with someone else be enough to make us unfaithful? What about a conventional relationship? New forms of infidelity have emerged, or "cyber infidelity". The American Psychological Association (APA) cautions about getting involved in cyber infidelity also suggests computerized tools to track down infidelities of a spouse or even a partner, pointing out the degree of emotional and moral seriousness behind the affairs taking place online. The pandemic provides the opportunity to imagine new sexual intimacies via sex toys and other forms of technology [2]. On the other hand, many couples are not ready to engage in online sex, and it is challenging for single adults to commit to casual sex, so (even) after the pandemic there will be many couples who will have to remodel and many singles who will seek a partner $[3,12]$.

Finally, the question of human rights, especially sexual ones, is very relevant, given that sexual orientations and gender identities other than the cis-heteronormative model expose people to greater vulnerability, which is increased during times of crisis in health systems ill-prepared for the influx of patients requiring emergency care. Earlier literature on the societal response towards pandemic developments allows for an initial understanding within the context of COVID-19.

\section{CONCLUSION}

Peoples needs for connection, love, flirtation and sexual expression remain whether they are confined or not. These social needs may be amplified or reduced, but they persist. The clinical significance of the dynamic interaction between sexual wellbeing, individual-level psychological factors, and the social environment during the pandemic needs to be understood. A future in which sexual intimacy must coexist with COVID-19 will necessitate the incorporation of scientific advances regarding health and risk into the praxis of health professionals.

Health professionals should take all these different aspects into account when planning for the complex variabilities in behavior that will soon emerge, and recommend that people enjoy their sexuality as much as possible within the best available practices for personal and social safety. The role of the digital platforms in this new scenario should be appreciated, evaluated, and considered a tool for improving sexual health, especially in such a novel scenario as is presented by COVID-19.

\section{REFERENCES}

1. Giami A. COVID-19 et sexualités: l'émergence d'un nouveau paradigme des sexualités. Sexologies. 2021;30:1-7.

2. Landry S, Chartogne M, Landry A. The impacts of COVID-19 lockdown on sexuality. Sexologies. 2020;29:173-80.

3. Schiavi MC, Spina V, Zullo MA, Colagiovanni V, Luffarelli $P$, Rago R, et al. Love in the time of COVID-19: sexual function and quality of life analysis during the social distancing measures in a group of Italian reproductive-age women. J Sex Med. 2020;17:1407-13.

4. Karagöz MA, Gül A, Borg C, Erihan İ, Uslu M, Ezer M, et al. Influence of COVID-19 pandemic on sexuality: a cross-sectional study among couples in Turkey. Int J Impot Res. 2020;16:1-9.

5. Banerjee D, Nair VS. "The Untold Side of COVID-19": struggle and perspectives of the sexual minorities. J Psychosexual Health. 2020;2:113-20.

6. Turban JL, Keuroghlian AS, Mayer KH. Sexual Health in the SARS-CoV-2 era. Ann Intern Med. 2020;173:387-9.

7. Sun CJ, Sutfin E, Bachmann LH, Stowers J, Rhodes SD. Comparing men who have sex with men and transgender women who use Grindr, other similar social and sexual networking apps, or no social and sexual networking apps: Implications for recruitment and health promotion. J AIDS Clin Res. 2018;9:757. 
8. Zattoni F, Gül M, Soligo M, Morlacco A, Motterle G, Collavino J, et al. The impact of COVID-19 pandemic on pornography habits: a global analysis of Google Trends. Int J Impot Res. 2020;28:1-8.

9. Eleuteri S, Terzitta G. Sexuality during the COVID-19 pandemic: the importance of Internet. Sexologies. 2021;30:e55-e60.

10. Scott RH, Smith C, Formby E, Hadley A, Hallgarten L, Hoyle A, et al. What and how: doing good research with young people, digital intimacies, and relationships and sex education. Sex Educ. 2020;20:675-91.

11. Coop Gordon K, Mitchell EA. Infidelity in the time of COVID-19. Fam Process. 2020;59:956-66.

12. Shilo G, Mor Z. COVID-19 and the changes in the sexual behavior of men who have sex with men: results of an online survey. J Sex Med. 2020;17:1827-34.

\section{ACKNOWLEDGEMENTS}

A special thank you to Boudoumi Fatiha, Djeradi Chaima, Nessaibia Hiba, and Nessaibia Mohamed. Without them, this work would never have been completed. the DGRSDT and the MESRS finance all our research work and provide us with the necessary tools.

\section{AUTHOR CONTRIBUTIONS}

$\mathrm{NI}, \mathrm{SR}, \mathrm{BZ}, \mathrm{TA}, \mathrm{TM}$ and $\mathrm{CL}$ : conducted a research and investigation process. $\mathrm{LA}$ : technical support and literature review. NI: supervised the project, wrote and submitted the manuscript, and responded to reviewer comments and suggestions. All authors have read and approved this manuscript before submission.

\section{COMPETING INTERESTS}

The authors declare no competing interests.

\section{ADDITIONAL INFORMATION}

Correspondence and requests for materials should be addressed to Issam Nessaibia.

Reprints and permission information is available at http://www.nature.com/ reprints

Publisher's note Springer Nature remains neutral with regard to jurisdictional claims in published maps and institutional affiliations. 